\title{
Predictive Optimization based Energy Cost Minimization and Energy Sharing Mechanism for peer-to-peer Nanogrid Network
}

\author{
FAIZA QAYYUM ${ }^{1}$, HARUN JAMIL ${ }^{2}$, FAISAL JAMIL ${ }^{1}$, AND DOHYEUN KIM ${ }^{1}$ \\ ${ }^{1}$ Computer Engineering Department, Jeju National University, Republic of Korea \\ ${ }^{2}$ Department of Electronic Engineering, Jeju National University, Republic of Korea \\ Corresponding author: F. Qayyum (e-mail: faizaqayyum@jejunu.ac.kr)
}

\begin{abstract}
The concept of distributed generation has made photovoltaic an integral source of energy in smart grid systems, especially in peer-to-peer energy trading frameworks that exploit excess power to fulfill the energy requirements of consumers in cost-efficient and eco-friendly manner. It is believed that P2P energy trading will dominate a significant portion of research in forthcoming power generation systems due to the excessive rise of energy demands across the globe. Despite a plethora of studies on energy optimization solutions in $\mathrm{P} 2 \mathrm{P}$ trading, minimizing nanogrid energy trading cost and efficient energy sharing between consumers and prosumers are deemed among the challenging problems. This study overcomes essential issues overlooked by the contemporary P2P energy trading models by introducing a predictive optimization-oriented nanogrid energy trading model. The proposed study encompasses two stages: (1) predictive optimization model which harnesses BD-LSTM-based forecasted energy parameters (energy load, energy consumption, and PV generation) that are later incorporated in PSO-enabled objective function to reduce nanogrid trading cost, (2) optimal energy sharing plan is devised to decide the role of nanogrids as prosumers or consumers by emphasizing the use of PV-produced energy. The proposed model is validated on the case study containing nanogrid houses data. The simulation provides detailed experiments by comparing the energy demand and response using the proposed energy sharing model. The outcomes yield that the energy sharing plan holds a significant potential to fulfill maximum energy requirements of nanogrid house in P2P cluster and significantly reduces the energy cost compared to grid.
\end{abstract}

INDEX TERMS Energy trading, energy prediction, predictive analysis, machine learning, optimization

\section{INTRODUCTION}

INCE the last decade, non-renewable energy resources $\checkmark$ such as coal, oil, and natural gas have been deemed primary sources for satiating the global energy demand [1] [2]. However, their adverse socio-economic and environmental impacts, such as the high cost of power generation, failure to fulfill energy requirements of the burgeoning population, and degradation of the environment, restrict the energy user's dependence over them [3] [4]. On the other hand, Renewable Energy Resources (hereinafter "RES") like solar, wind, tidal, nuclear, hydro, biomass hold a promising potential to generate eco-friendly energy. Therefore, RES based energy resources are in tandem with generally and has also been favored by eco-friendly organizations. Moreover, renewable energy resources generate energy with lower production prices and transmission cost [6], [7]. In the contemporary era, the sheer dependence of power grids over non-renewable sources is a recipe for environmental disaster and failure to bridge mushrooming energy demand-supply gap; therefore, power grids require lion's share of energy supply from RES. RES has revolutionized the energy sectors of the present era with the increasing deployment of distributed generators and Energy Storage Systems (ESS) [8] . The adverse impacts of RES in the demand side are mitigated with the initiation of microgrid and nanogrid (NG). A nanogrid is a simpler form of a microgrid that involves a single load encompassing a single house [9]. In other words, NG is deemed a single entity for administration, voltage, and reliability, and at least one gateway at the outside of NG. The main feature of NG is its potential to get connected with other NG, forming a nanogrid 
cluster [10]. This ease of interconnectivity has introduced the concept of P2P energy trading, which fosters the use of renewable energy resources, evading the reliance on the utility grid resulting in reduced nanogrid cost. $\mathrm{P} 2 \mathrm{P}$ energy trading implements the same notion as $\mathrm{P} 2 \mathrm{P}$ networking in Computer Science wherein the systems in $\mathrm{P} 2 \mathrm{P}$ networks are horizontally disseminated, indicating that each of them has symmetric interaction an [9], [11]. The radical evolution of RES enables peer-to-peer (P2P) energy trading between homes or buildings [12]. P2P energy trading follows the notion of "P2P economy", and is executed within the local energy distribution network [13]. The energy trading process involves two or more peers, often referred to as consumers and prosumers. Energy consumers are the peers who can generate energy to fulfill their energy requirements. In contrast, the intelligent smart grid infrastructures allow the peers to generate surplus energy and inject it into the distribution systems, thus assuming prosumers' role to produce and trade surplus energy with other peers in the network. The core objective of $\mathrm{P} 2 \mathrm{P}$ energy trading is to mitigate the intermediation of conventional energy suppliers (i.e., power grid) and fulfill energy demands in a cost-efficient manner [14, 15]. The energy trading operation employs Information and Communication Technologies (ICT)-based online services to enable interaction among peers [16]. The peers involved in the trading operation, i.e., consumer and prosumer, both have an instrumental role in the trading process. The efficient energy trading operation requires optimal planning to fulfill real-time energy demand at a minimal energy cost. The scientific community has presented various P2P energy trading models to enhance the trading mechanisms facilitating both consumers and prosumers in terms of improved energy demand and response signal and reduced energy cost [17] [18]. Optimization plays a pivotal role in providing sustainable smart solutions [19]-[22]. Energy optimization selects the best/optimal option from multiple solutions for efficient energy operation. The model [23] optimizes the energy trading among two microgrids harnessing a central controller to operate in an islanded mode. Moradzadeh and Tomsovic (2013) [24] implemented a two-stage pricing mechanism to provide economical energy cost. Lauinger et al. (2016) [25] adopted linear programming optimization to reduce $\mathrm{CO} 2$ emissions and electricity cost in DER homes. An incentivebased renewable energy sharing scheme [26] uses surplus energy transmission among peers. A coalitional game-based energy trading scheme[27] suggests an optimal energy price for energy trading. The study [28] allows multiple prosumers to involve in energy trading by proposing a cooperative distributed power generation. The outcomes were evaluated by assessing electricity consumption and cost. The wind power producers were facilitated with the bidding-based P2P energy trading method presented by [29] Vahedipour-Dahraie et al. (2020). Umer et al. [30] implemented a communicationoriented P2P energy trading model to provide economical energy trading solutions to prosumers. Paudel et al. (2020) [31] suggested a decentralized market clearing strategy model.
Esmat et al. (2021) [32] implemented the same idea as Paudel et al. (2020) [31] to provide secure energy trading using blockchain. The recent trend in the energy trading sector involves the paradigm of machine learning to reveal the hidden patterns from the energy corpus to form a predictive model and use the derived knowledge for efficient decisionmaking [33-34]. Day-ahead information forecasting in the energy trading sector has been proven helpful for energy providers to schedule the power loads or predict energy cost to ensure the balance between energy demand and production at an optimal cost [35]. The strategies devised from energy forecasting parameters reduce production costs and better future capacity planning [13]. In [36], authors have employed a machine learning-based forecasting model to predict energy demands to optimize the overall energy operation of the microgrid. Similarly, in [37], the authors presented a hybrid energy management system incorporating fuzzy logic and machine learning to solve the multi-objective optimization problem using linear programming. The experiments carried out by (Ma et al., 2016) [38] validated that day-ahead pricing can significantly reduce peak loads and energy costs. The day-ahead pricing information was incorporated to schedule the appliances as per user comfort while ensuring the minimal cost (Ma et al., 2016) [38]. Similarly, the PV energy trading model was suggested using forecasted PV power information for load scheduling (Zhang et al., 2019) [39]. Anoh et al. (Anoh et al., 2019) [40] formed a virtual microgrid connecting the consumers and prosumers located at a minimum distance and provided minimal energy purchasing cost of PV power. Energy trading cost optimization algorithm was implemented to enable energy sharing at a minimal cost Alam et al. (2019) [41] . Most of the contemporary nanogrid energy trading systems focus on managing energy inside a single entity i.e., consumers or prosumers. Prousmer-oriented enegry trading framework has been suggested in Paudel et al. (2018), [42] Tushar et al. (2020). [43] Paudel et al. (2018) [42] developed game-theoretic model for a microgrid infrastructure to provide optimal energy cost plan for prosumers. The scientific community has successfully provided costefficient and eco-friendly energy solutions. However, various essential aspects are needed to be incorporated to improve the performance of energy trading frameworks, ensuring maximum profits to both consumers and prosumers. Moreover, smart grid energy trading can significantly benefit from the history learnings of load's pattern data, reducing the trading cost to a great extent. We believe that intelligent integration of predictive energy parameters with optimal energy cost and energy sharing planning can significantly reduce the nanogrid energy trading cost. In this study, we present an intelligent $\mathrm{P} 2 \mathrm{P}$ nano-grid energy trading platform that integrates prediction outcomes implemented using BD-LSTM and PSObased optimization mechanisms to meet the real-time energy demands at a minimum cost.

The salient contributions of the proposed framework are as follow: 
- Provision of an intelligent P2P energy trading model that ensures optimal energy sharing among peers and also provides an optimal energy trading cost solution;

- Implementation of analytical data module based on data mining methods to reveal important hidden aspects pertaining to energy consumption, energy load and PV generation to beneficiate energy distributors and peers to make informed decisions to increase the consumption of local DER generations by early prediction of important energy attributes

- An intelligent time-aware energy sharing plan is devised, which decides the role of nanogrids as prosumer or consumer and prefers the use of PV generated energy over grid energy for local trading;

- The optimal energy trading cost strategy is implemented using an objective function that takes the actual and predicted values of energy load and returns the minimized cost by implementing the PSO-enabled optimization method;

- The significance of the proposed model is validated by presenting a case study wherein data of 12 nanogrid is obtained from the residential community of Jeju City, South Korea.

The remainder of the paper is structured as follows. Section 2 illustrates the system model for the architecture. Section 3 provides the simulation results carried out by considering a case study encompassing date of nanogrid houses. Finally, section 4 concludes the paper and highlighting the successful contributions of the proposed study.

\section{METHODOLOGY}

This section encompasses methods employed to implement the proposed energy trading for optimal P2P energy exchange within a nanogrid cluster. The considered data set of 12 nanogrid houses that contain rooftop PV panels to meet energy requirements of energy appliances. The overall structure of the proposed model is shown in 1.

Firstly, energy data of all the nano-grid houses is thoroughly analyzed to grasp their individual behavior. The data values of the parameters contained some missing records which was addressed using kNN imputation method. The analysis outcomes are detailed discussed in section 3. For energy cost data, we have considered the SMP cost and DR cost data provided by (KEPCO).The analyzed parameters are passed to the prediction module, which implements BDLSTM model to predict energy load, energy consumption, PV generation, and electricity cost. As mentioned earlier, this study focuses on optimizing two important aspects related to energy trading, (1) optimize energy trading cost and (2) optimal energy exchange plan among nanogrid houses connected within a cluster. The actual and predicted energy parameters also serve as an input to the optimization modules.

Each nanaogrid contains a smart meter that monitors, records, and transmits information pertaining to energy load demand and PV power production.

\section{A. NANOGRID P2P ENERGY TRADING NETWORK}

This section delineates details regarding the power management of a nanogrid cluster (i.e., connected nanogrids) used within the $\mathrm{P} 2 \mathrm{P}$ energy trading framework. Each nanogrid in the network is assigned a role as a consumer or prosumer prior implementing the proposed optimization modules. Thus, energy "sell" or "buy" trade mode is enabled prior to initiating the trading process. To initiate energy trading among peers, the first thing is to ensure the supply-demand relationship between nanogrids. Once the relationship is ensured, the nanogrid can trade energy in a peer-to-peer fashion. Nanogrids rely on two energy resources, utility, and PV, to fulfill their energy requirements. All the nanogrids in the network are connected to the utility grid in the form of point of common coupling (PCC). The utility grid is employed to fulfill energy requirements when a local cluster fails to meet energy requirements due to unfavorable conditions incurred by the renewable. On the other hand, when a nearby nanogrid fulfills its energy requirements and holds surplus energy produced by PV, the energy could be sold out among connected nanogrids in a peer-to-peer manner.

\section{B. BIDIRECTIONAL LONG SHORT-TERM MEMORY (BD-LSTM) FORECASTING MODEL}

Energy parameters encompassing energy loads, energy consumption, PV generation, and energy cost are predicted using BD-LSTM model. We believe that prediction of such crucial energy parameters can play an effective role in revealing useful time-series based hidden patterns in the data to beneficiate in the applications pertaining to future energy demands. First, let us explain the detailed structure of conventional LSTM. It holds a particular memory cell to store the timestamp-based information, which provides LSTM with an additional ability than conventional RNNs [35]. A plethora of existing studies has proven the significance of prediction models in energy applications in terms of early forecasting leading to maximum welfare. For instance, in the context of the proposed study, $\mathrm{P} 2 \mathrm{P}$ energy trading based on forthcoming load requirements and PV power production is performed based on the assumption that it may result in more costefficient $\mathrm{P} 2 \mathrm{P}$ electricity trading. Let us first explain the basic structure of BD-LSTM. Unlike LSTM, BD-LSTM trains two models wherein one model learns the pattern of input and later learns the reverse of the pattern. The multi-layer LSTM model of a cell at layer 1 and time $\mathrm{k}$ in the forward direction is executed using equations (1-6). The following equations represent the gates that are part of LSTM which transforms it into BD-LSTM.

$$
\begin{gathered}
\text { input gate }: g_{g(k)}^{\prime}=\partial \quad X_{k}^{\prime}(h)_{k}^{l-1}+Y_{k}^{\prime}(h)_{k-1}^{l-1}+c_{k}^{\prime} \\
\text { forget gate: } f_{g(k)}^{\prime}=\partial \quad X_{f}^{\prime}(h)_{k}^{\prime-1}+Y_{f}^{\prime}(h)_{k-1}^{\prime-1}+c_{f}^{\prime} \\
\text { output gate: } O_{g(k)}^{\prime}=\partial \quad X_{o}^{\prime}(h)_{o}^{\prime-1}+Y_{o}^{\prime}(h)_{k-1}^{\prime-1}+c_{o}^{\prime} \\
\text { candidate gate: } C_{g(k)}^{\prime}=\tanh X_{C}^{\prime}(h)_{c}^{\prime-1}+Y^{\prime}(h)_{k-1}^{\prime-1}+c_{o}^{\prime}
\end{gathered}
$$




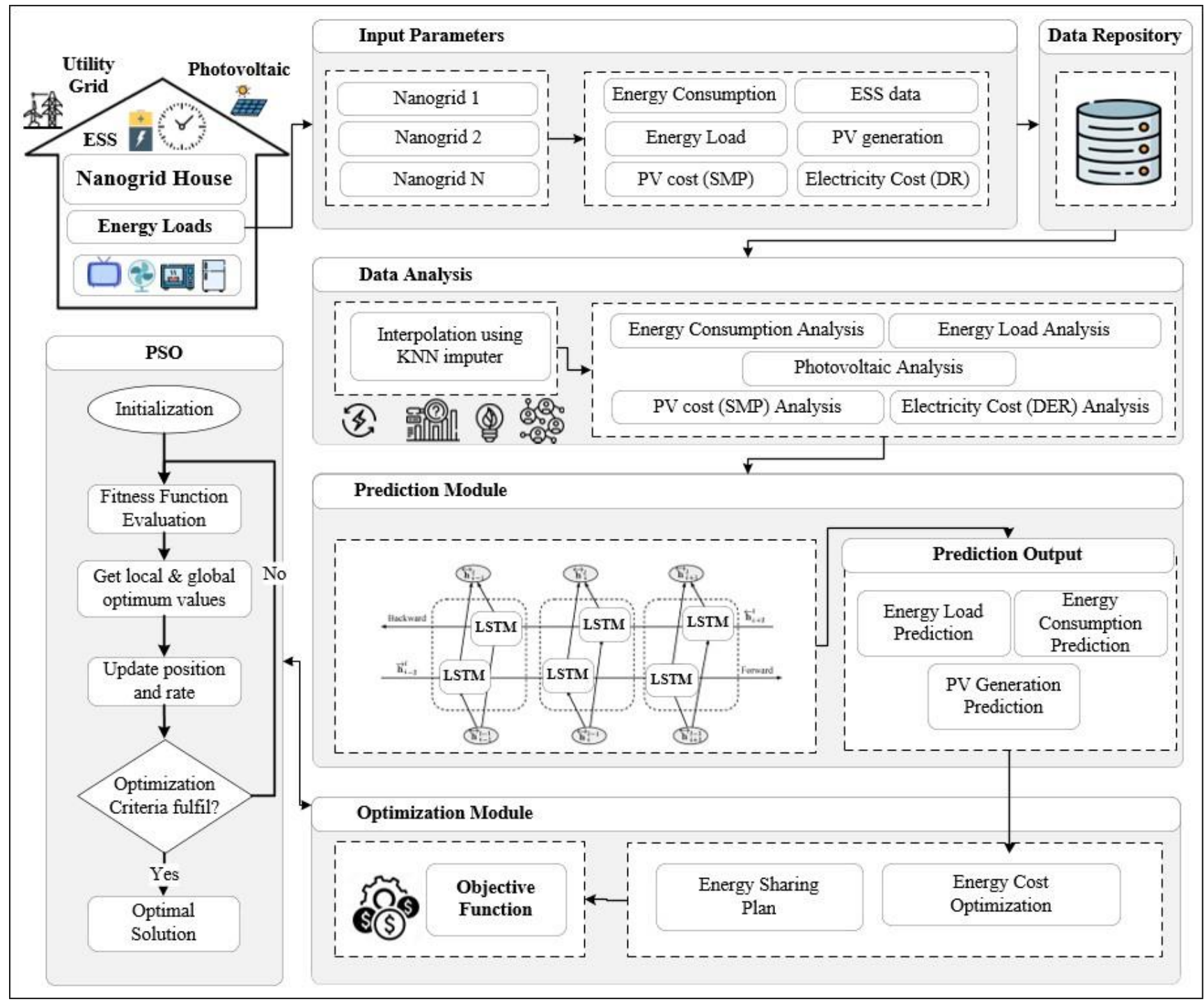

FIGURE 1. Architecture of Predictive Optimization based Energy Cost Minimization and Energy Sharing Plan for peer-to-peer Nanogrid

$$
\begin{gathered}
\text { cell state: Cell' }{ }_{g(k)}^{\prime}=f_{i}^{\prime} * \text { Cell }_{k-1}^{\prime}+k_{i}^{\prime} * C_{g(k)}^{\prime} \\
\text { hidden state } h_{k}^{\prime}=o_{i} * \tanh \text { Cell }{ }_{k}^{\prime}
\end{gathered}
$$

In the above equations (1-4), $X^{\prime}$ represents weight metrics among layer's cell (1-1), and $Y^{\prime}$ represents weight matrices among continuous cells of layers 1 , and $C^{\prime}$ represents the bias vector of each layer. The weight matrices and the bias values of the cells are broadcasted with the length of the sequence to reduce the number of hidden neurons and weights in the network. The “*” symbol in equations (5-6) depicts elementwise multiplication. The BD-LSTM traverses the information in two directions, forward and backward, which is done harnessing two separate LSTM layers. The hidden state for the forward direction is computed using equation 6 . Similarly, the same formula is employed to calculate backward hidden state and traversed in the backward direction.

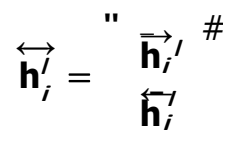

In the equation 7, 1 represents the input layer. Compared to LSTM, BD-LSTM can interpret the association between elements in the full sequence by processing the information in both directions. In addition, the parameters sharing method employed by BD-LSTM consumes less memory than the conventional CNN and DNN; therefore, in this study, we employ BD-LSTM as a forecasting model to predict load demands and energy consumption, PV generation, and energy cost. The model comprises six hidden layers. We employ the trial and error technique [52] to determine the parameters to the input layer and the number of hidden layers in the BD-LSTM model. The number of inputs and outputs to be 
TABLE 1. Acronyms used in Objective Function and Energy Sharing Plan

\begin{tabular}{|l|l|l|l|}
\hline Symbols & Meaning & Symbols & Meaning \\
\hline $\mathrm{C}$ & Cost of energy & $\mathrm{k}_{o}$ & $\begin{array}{l}\text { Intercept in real } \\
\text { time pricing model }\end{array}$ \\
\hline $\mathrm{N}$ & Time interval & $\mathrm{NG}$ & nanogrid \\
\hline $\mathrm{m}$ & $\begin{array}{l}\text { No. of consumers } \\
\text { i.e., Homes) }\end{array}$ & $\mathrm{k}$ & Nanogrid index \\
\hline $\mathrm{i}$ & $\begin{array}{l}\text { Interval of time } \\
\text { (i.e., an hour) }\end{array}$ & $\mathrm{t}$ & Time-interval \\
\hline $\mathrm{X}_{i m}$ & $\begin{array}{l}\text { Power of m } \\
\text { consumer in interval i }\end{array}$ & $\mathrm{ess}$ & $\begin{array}{l}\text { Energy storage } \\
\text { system }\end{array}$ \\
\hline $\mathrm{T}$ & Length of interval & $\mathrm{D}$ & Energy load \\
\hline $\mathrm{E}_{m}$ & $\begin{array}{l}\text { Initial energy usage of } \\
\text { m consumers }\end{array}$ & $\mathrm{PV}$ & Photovoltaic \\
\hline $\mathrm{EC}_{m}$ & $\begin{array}{l}\text { The capacity of } \\
\text { m consumers }\end{array}$ & $\mathrm{SS}$ & Self-supplied \\
\hline $\mathrm{p}_{m a x}$ & Maximum power & $\mathrm{RE} / \mathrm{re}$ & Remaining energy \\
\hline $\mathrm{r}$ & $\begin{array}{l}\text { Final energy ratio } \\
\text { of m consumer }\end{array}$ & $\mathrm{S}$ & Shared energy \\
\hline $\mathrm{z}_{\boldsymbol{i}}$ & $\begin{array}{l}\text { Total load in } \\
\text { interval i }\end{array}$ & $\mathrm{DE}$ & Discharging energy \\
\hline $\mathbf{L}_{\boldsymbol{f i}}$ & $\begin{array}{l}\text { Forecasted load in } \\
\text { interval } \mathrm{i}\end{array}$ & $\mathrm{G}$ & $\begin{array}{l}\text { Energy bought from } \\
\text { utility grid }\end{array}$ \\
\hline $\mathrm{K}_{1}$ & $\begin{array}{l}\text { Slope in the real-time } \\
\text { pricing model }\end{array}$ & & \\
\hline
\end{tabular}

passed to the prediction model is decided by evaluating the root-mean-squared error (RMSE). The input layer of BDLSTM model takes the input of load as $\mathrm{L}(\mathrm{k}-\mathrm{i})$ to $\mathrm{L}(\mathrm{k})$, which returns the output as $\mathrm{L}(\mathrm{k}+\mathrm{i})$ wherein $\mathrm{i}=1,2 \ldots, \mathrm{m}$. ADAM optimizer is harnessed to find the weights and accuracy at each epoch. RMSE measure is considered as a log loss function which validates performance of the proposed model, computed using equation 9. A denotes the actual predicted value, and $\mathrm{P}$ denotes the same predicted value in time interval $\mathrm{t}$, wherein the value of $\mathrm{t}$ is from 1 to $\mathrm{k}$.

$$
R M S E=\overline{k_{t=1}^{k k}} A_{t(i)}-P_{t(i)}{ }^{2}
$$

\section{MINIMIZE NANOGRID ENERGY TRADING COST}

This section explains the objective function proposed to reduce nanogrid cost for consumers. The objective function is implemented using PSO, as shown in the architecture diagram Figure 1. The objective function considers the actual and predicted loads to reduce energy trading cost. Table 1 illustrates the acronyms used in the two optimization modules.

Equations (9-14) present the objective functions which focus on reducing the trading cost among connected peers.

$$
\operatorname{Min}_{C_{i}}=k_{o} z_{i}+\frac{k_{1}}{2} z^{2}-k d_{f i}+\frac{k_{1}}{2} L_{f i}^{2}
$$

The constraints on equation 10 represents the relationship $\mathrm{b} / \mathrm{w}$ total load in an interval and energy to an individual consumer for energy trading.

$$
z_{i}=L_{i b f}+\sum_{m \varepsilon M} X_{m i} f_{m i} \quad \text { (for all ien) }
$$

where,

$C_{f}$ $f_{m i}=1$, if interval i falls within energy flow of $m$ consumer $o$ otherwise

$$
0 \leq E_{m}+\sum_{m \varepsilon N} \mathrm{TX} X_{m} f_{m} \leq E C_{m}
$$

Equation 13 represents the final energy of $m$ th consumer at the end of the interval which would not be greater than the permissible amount of energy.

$$
E_{m} \sum_{i \varepsilon N} \mathrm{TX}_{m i} f_{m i}>r_{m} E C_{m}
$$

The constraints shown in equation 14 specifies the lower and upper bound of energy flow for consumers.

$$
0 \leq x_{m i} \leq p \quad \max
$$

\section{ENERGY EXCHANGING MECHANISM}

The nanogrids connect to the utility grid via BD-DC-AC converters so that energy remains balanced. If a nanogrid holds surplus energy, the converter will turn on its inverter mode and send the remaining energy back to the utility grid. In the opposite situation, the converter would feed the energy from the utility grid. The proposed energy exporting and importing strategy is shown in Figure 2. Each module of the figure is explained in this section.

Let NG be a set of nanogrids in the proposed energy trading network and $\mathrm{n}$ be number of nanogrids.

$$
N G=\left\{N G_{1}, N G_{2}, \ldots, N G_{n}\right\}
$$

Let \pm 1 be a value used for energy selling and buying. For instance, if a nanogrid is assigned " $+1 "$, it shows that the nanogrid has an exceeding amount of energy (i.e., surplus energy) that can be sold to other nanogrids in the network/cluster. Similarly, "-1" indicates that a nanogrid does not hold adequate energy to fulfill its demands and needs requires energy from connected nanogrids (first priority) or the utility grid. Let ESS represents a set of energy storage system installed in each nanogrid. For instance,

$$
E S S=\left\{\operatorname{ess}_{1}, \operatorname{ess}_{2}, \ldots, \operatorname{ess}_{n}\right\}
$$

where $\mathrm{n}$ represents total number of ESS which would be same as numbe of nanogrid houses.

Let $\mathrm{t}$ be a timespan and $\mathrm{D}$ be the load demand. Thus, $D_{k}(t)$ represents the load demand of $k^{\text {th }}$ nanogrid at time t. Similarly, let $P V{ }_{k}(t)$ be the energy generated by photovoltaic $(\mathrm{PV})$ of $k^{\text {th }}$ nanogid at time t, which can either be employed to charge essk or to meet $D_{k}(t)$. In addition, the surplus energy produced by PV is utilized for selling to other NG in need. The self-supplied energy generated by PV to meet loads demand of its nanogrid is referred as: 


$$
S S_{k}(t)=\operatorname{minimum}\left(D_{k}(t), P V_{k}(t)\right)
$$

The ESS unit comprises batteries used to store energy generated by PV, and a bi-directional DC-DC converter. The energy remained in ess at time-span $t$ is termed as, $R_{k}(t)$. Both the factor decides decision taken for ess charging, i.e, $D_{k}(t)$ and $P V{ }_{k}(t)$ and the amount of energy traded with other nanogrids.

The following scenarios are being considered for P2P energy trading.

- If trading function $=+1$ : The preference for energy exporting would be given to PV, i.e., surplus energy produced by $P V{ }_{k}(t)$. And, if there is no surplus energy, then the energy stored in essk will be used for trading.

- If trading function= -1 : The bought energy can only be utilized to supply, $D_{k}(t)$, not to be stored in ess .

The energy remained after energy trading at time interval $t$ is denoted as:

$$
R E=\left\{r e_{1}(t), r e_{1}(t), \ldots, r e_{n}(t)\right\}
$$

wherein $r e$ shows energy remained in es of $\mathrm{k}$ nanogrid at time t. The re holds constraint depending on ess capacity. The constraint is:

$$
r e_{\min , k} \leq r e_{k}(t) \leq r e_{\max , k}
$$

$r e_{(\max , k)}$ is the total capacity of ESS in $(\mathrm{kWh})$ and $r e_{(\min , k)}$ is the minimum energy of ess fixed by DoD to evade from excessive discharging.

The energy shared by each nanogrid is termed as, $S_{k}(t)$, which denotes the amount of shared energy by $k^{\text {th }}$ nanogrid at time t. $S_{k}(t)$ will be employed as a decision factor for energy trading. The amount of shared energy also assists in determining the amount of surplus energy of the respective nanogrid. For instance, if the shared energy is greater than zero, the trading function will become +1 , otherwise becomes -1 . Following are the constraints imposed for energy sharing.

$\Sigma_{k} \oint_{k}(t)$ indicates the energy left in NG. $S_{k}(t)$ must lie between 0 and the maximum amount of energy shared at time $t$. The maximum value of $S_{\max , k}$ is determined by the rated power of the interface BD-DC-DC converter of $N G_{k}$. $\Sigma$ Similarly, surplus energy generated by PV is termed as, $k\{$ Surplus $k(t)\}$.

The following function specifies the energy value to be traded.

$$
\begin{array}{ll}
\text { Surplus } k(t)= & \\
\min _{0,}\left(P V_{k}(t)-D_{k}(t)\right), \text { Surplus max,k } & \\
& N G_{k} \in+1 \\
& N G_{k} \in-\frac{1}{(15)}
\end{array}
$$

The value of Surplus max,$k$ is determined based on two factors: (1) Maximum amount of energy in ess $k$ at time t, determined by the rated power of the DC-DC. converter, and (2) remax,k.
The amount of discharged energy from essk, used to meet the energy load for k nanogrid, is termed as:

$$
\begin{array}{cc}
\quad D E_{k}(t)= & \\
0, & N G_{k} \in+1 \\
\left\{\min \left(D_{k}(t)-P V_{k}(t)\right), D E_{\max , k}\right\} & N G_{k} \in-1
\end{array}
$$

$D E_{\text {max }, k}$, is amount of maximum energy discharged from essk within time-span $\mathrm{t}$, that is determined by the remained energy of es and rated power of BD-DC-DC converter. The equations that decide the energy flow of +-1 , is designed as follows:

$$
\begin{aligned}
& \text { C } \\
& \left.\mathrm{re}(\mathrm{t}+1)=\mathrm{rek}^{k}(t)+\operatorname{Surplus} k(t)-S E \nless t\right) \quad N G k E+1 \\
& r e(t+1)=\operatorname{re}_{k}(t)-D E_{k}(t) \\
& N G_{k} \in-1
\end{aligned}
$$

For energy buying (i.e., +1 ), essk must follow these two conditions:

$$
\begin{aligned}
& \text { if (NG }==+1) \\
& \text { if ( Surplus } \left.{ }_{k}(t) \leq E S_{k}(t)\right) \\
& \text { Dicharging mode }==\text { TRUE } \\
& \text { Surplus }{ }_{k+1}(t)=E S_{k}(t)-\text { Surplus }_{k}(t) \\
& \text { if ( Surplus } \left.{ }_{k}(t)>E S_{k}(t)\right) \\
& \text { Charging mode }==\text { TRUE } \\
& \text { Surplus }_{k+1}(t)=\text { Surplus }_{k}(t)-E S_{k}(t)
\end{aligned}
$$

In contrast to the conditions mentioned for $\mathrm{NG}=+1$, for $\mathrm{NG}=-1$, essk cannot operate during charging. Various operational constraints are imposed according to energy consumption and available energy of nanogrids. For $\mathrm{NG}=+1$, the amount of traded energy (TE) is termed as:

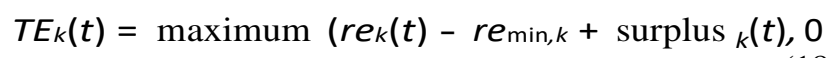

Equation 18 holds the following constraints:

$$
-R E_{k}(t) \leq E S_{k}(t) \leq 0
$$

The total amount of energy shared by +1 nanogrid must not exceed the total energy required by -1 nanogrid, whereas, the shared amount of energy that is (-1) nanogrid buys from (+1) cannot exceed their energy available for selling.

\section{CASE STUDY}

To verify the experiments, we employ a data set of 12 nanogrids from the residential community of Jeju City, South Korea. The data is obtained from smart meters installed in the nanogrids, intermingled with other requisite parameters to implement the proposed model. It is assumed that the smart meter can control and monitor the energy operation of all the loads and devices. The smart meter contains current signals and raw voltages. The energy consumed by a nanogrid is calculated via discrete signals. Table 2 presents an overview 


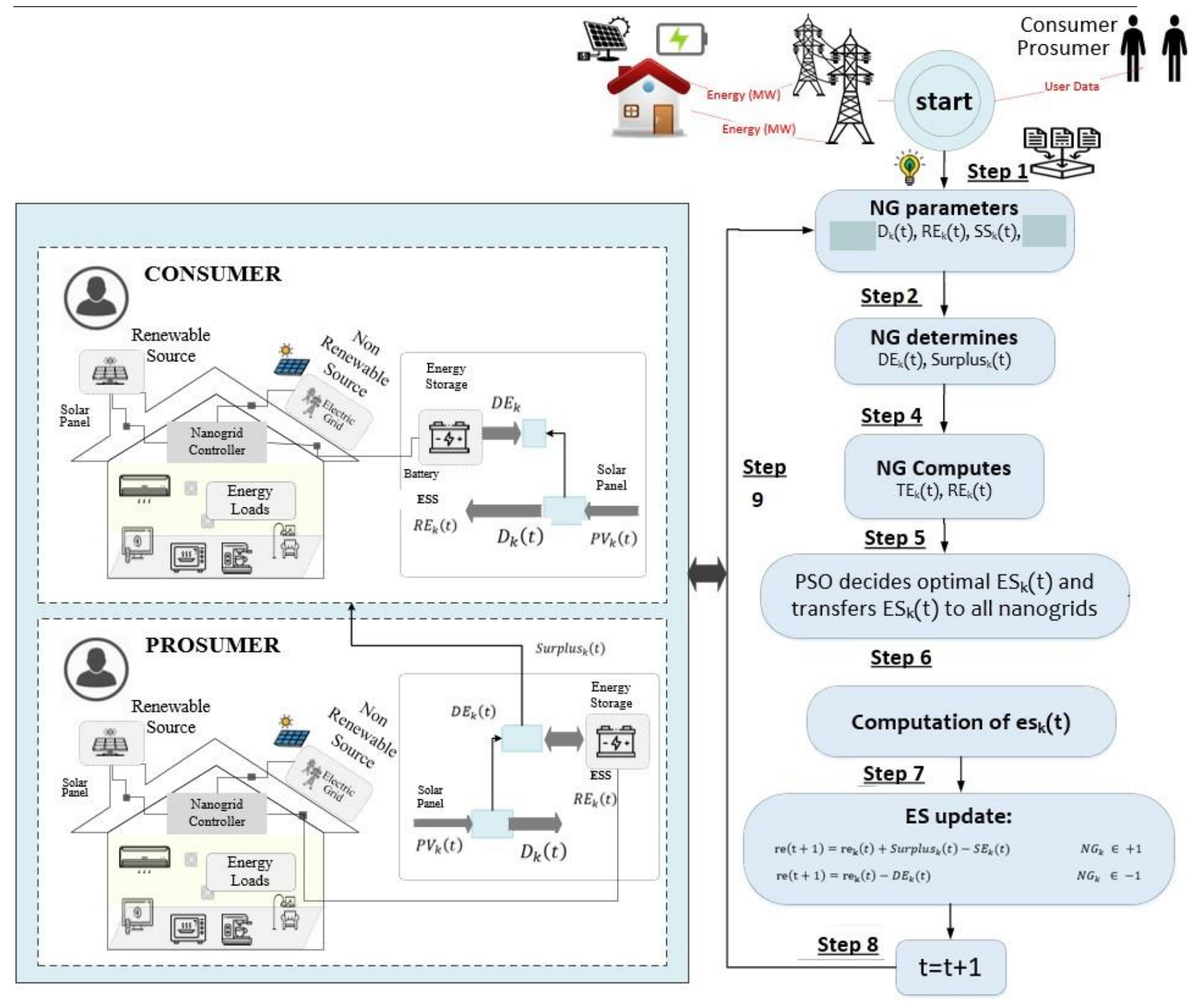

FIGURE 2. Energy Exporting and Importing Strategy of the proposed Energy Sharing Plan

of the employed energy data that contains energy load and PV generation data produced on daily and weekly by the houses and their respective discharging power $(\mathrm{kW})$. The minimum SoC level of the ESS system is $30 \%$, and PV capacity is 2.5 $\mathrm{kWp}$. The simulation is conducted in MATLAB. Contemplating a situation where the considered NGs hold a minimum geographical distance, the PV of 12 NGs would have similar data obtained from the actual installed rooftop PV.

\section{A. DATA ANALYSIS}

This section delineates the outcomes attained by performing descriptive analysis on the energy data. The weekly-based analysis is performed on the data set of the considered nanogrid houses in the following ways: (1) energy consumption analysis, (2) energy load analysis, (3) PV generation
TABLE 2. Energy Load and Generation based Nanogrid Parameters

\begin{tabular}{|c|c|c|c|c|c|}
\hline \multirow{2}{*}{$\begin{array}{c}\text { Nano- } \\
\text { grids }\end{array}$} & \multicolumn{2}{|c|}{$\begin{array}{c}\text { Energy Loads } \\
\text { (kWh) }\end{array}$} & \multicolumn{2}{c|}{$\begin{array}{c}\text { PV Generation } \\
(\mathbf{k W h})\end{array}$} & $\begin{array}{c}\text { Discharging } \\
\text { ESS power } \\
(\mathbf{k W})\end{array}$ \\
\cline { 2 - 5 } & Weekly & Daily & Weekly & Daily & \\
\hline NG-1 & 74.73 & 10.67 & 71.61 & 10.23 & $3 \mathrm{~kW}$ \\
\hline NG-2 & 64.71 & 9.24 & 72.41 & 10.34 & $2.5 \mathrm{~kW}$ \\
\hline NG-3 & 41.22 & 5.88 & 69.02 & 9.86 & $2.8 \mathrm{~kW}$ \\
\hline NG-4 & 18.44 & 2.63 & 68.88 & 9.84 & $3.2 \mathrm{~kW}$ \\
\hline NG-5 & 159.14 & 22.73 & 75.42 & 10.77 & $3.8 \mathrm{~kW}$ \\
\hline NG-6 & 107.21 & 15.31 & 71.33 & 10.19 & $2.5 \mathrm{~kW}$ \\
\hline NG-7 & 94.22 & 13.46 & 72.61 & 10.37 & $2.8 \mathrm{~kW}$ \\
\hline NG-8 & 108.33 & 15.47 & 64.03 & 9.14 & $3.2 \mathrm{~kW}$ \\
\hline NG-9 & 181.89 & 25.98 & 59.33 & 8.47 & $3.3 \mathrm{~kW}$ \\
\hline NG-10 & 225.46 & 32.20 & 76.02 & 10.86 & $2.5 \mathrm{~kW}$ \\
\hline NG-11 & 197.12 & 28.16 & 67.74 & 9.67 & $4 \mathrm{~kW}$ \\
\hline NG-12 & 213.41 & 30.48 & 67.31 & 9.61 & $2.5 \mathrm{~kW}$ \\
\hline
\end{tabular}


analysis, and (3) energy cost analysis.

\section{1) Energy Consumption}

This section delineates the energy consumption analysis of the considered nanogrid homes that can act as a consumer or prosumer based on their energy consumption and load. The home appliances encompassing all the loads have their power rating while operating. Figure 3 shows the average energy consumption analysis for each day of a week. Overall, the houses exhibit an identical energy consumption behavior. The NG-2 has a minor daily conusmption, i.e., around $3 \mathrm{kWh}$, and NG-10 has the highest energy consumption of around 32 $\mathrm{kWh}$ compared to other houses.

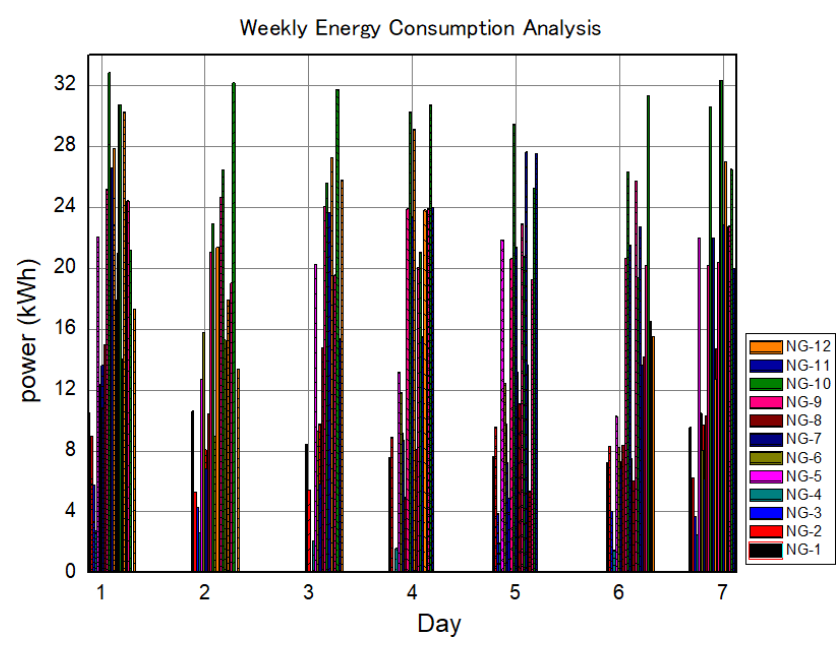

FIGURE 3. Weekly Energy Consumption Analysis of Nanogrid Houses

\section{2) Energy Load}

Similarly, energy load analysis of the NGs is shown in Figure 4.

, similar to the analysis performed for energy consumption (shown in Figure 4). Overall, the NG-10 has the highest value of energy load, i.e., $32.2 \mathrm{~kW}$, and NG-4 holds the lowest energy load of $2.6 \mathrm{~kW}$, followed by NG-3 with around 5.9 $\mathrm{kWh}$ weekly. The same can be seen for each day of the week while the rest of the houses have moderate energy loads.

\section{3) PV Generation Analysis}

An analysis of energy generated from photovolatic (PV) arrays is considered to grasp the behaving pattern of PV generation in different days of a week entirely depending on the weather condition. Figure 5 shows the PV energy generation analysis for seven days of a week of all the considered NGs. It is evident from the figure that NG3 exhibits the lowest value of PV energy generation, i.e., around $8.47 \mathrm{KWh}$, followed by NG-4, NG-11, NG-7, N-12, and reaching the highest PV generation value produced by NG-8 of about $10.86 \mathrm{kWh}$. The weekly ratio delineates the lowest value as $59.33 \mathrm{kWh}$ by NG-5 and maximum by NG-6 at around $76 \mathrm{kWh}$.

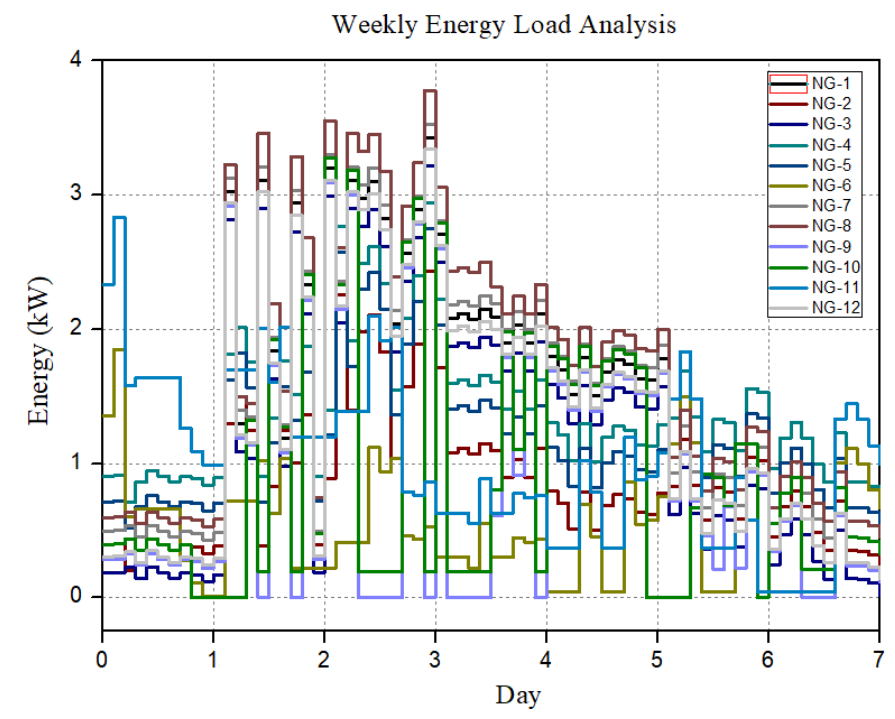

FIGURE 4. Weekly Energy Load Analysis of Nanogrid Houses

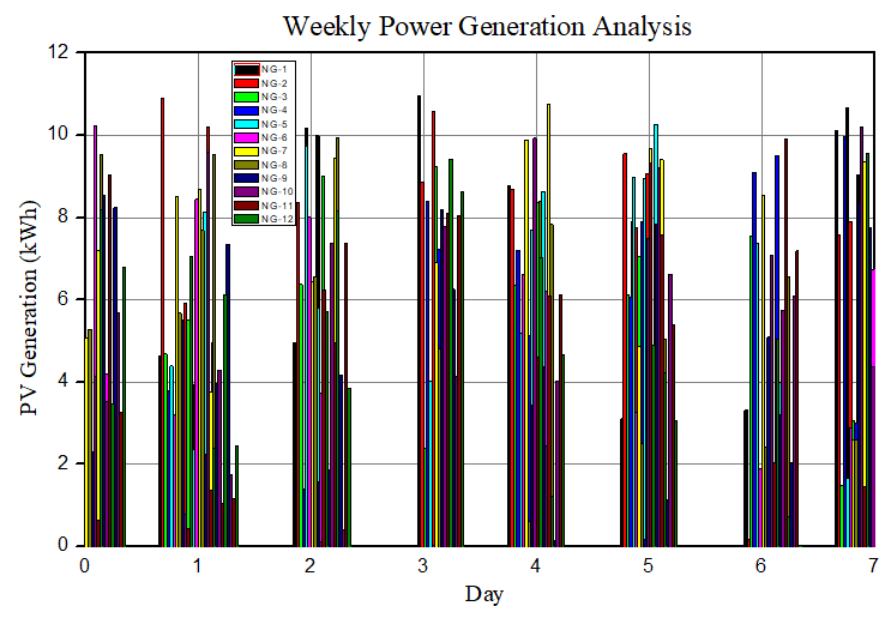

FIGURE 5. Weekly Photovoltaic(PV) Generation Analysis of Nanogrid Houses

\section{4) Energy Cost Analysis}

Electricity cost data considered in this study is taken from the demand response program (DR) proposed by the Korea Electric Power Corporation (KEPCO). DR scheme provides incentives to those consumers who utilize less amount of energy during peak hours. The DR scheme helps in reducing power plan emission, enhancing the reliability of power systems, and less reliance upon overseas fuels [51]. The Korea Electric Power Corporation (KEPCO) determines the electricity rate using DR program. The DR program specifies the rate for the energy supplied by the utility grid. The electricity price determined by DR scheme ranges in $\$ 0.05 / \mathrm{kWh}$ for 23:00-09:00 time intervals, $\$ 0.1 / \mathrm{kWh}$ for 9:00-10:00, 12:00-13:00, 17:00-23:00 time intervals, and $\$ 0.18 \mathrm{kWh}$ for 10:00-12:00, 13:00-17:00 time intervals, as visualized in Figure 8. Similarly, energy trading rate specified by renewable energy certificates and system marginal price 
TABLE 3.

\begin{tabular}{|l|l|l|}
\hline No. & Predictive Parameter & RMSE \\
\hline 1 & Energy Load & 1.45 \\
\hline 2 & Energy Consumption & 1.98 \\
\hline 3 & PV Generation & 1.26 \\
\hline
\end{tabular}

(SMP) is determined by Korea Power Exchange (KPX) [23].

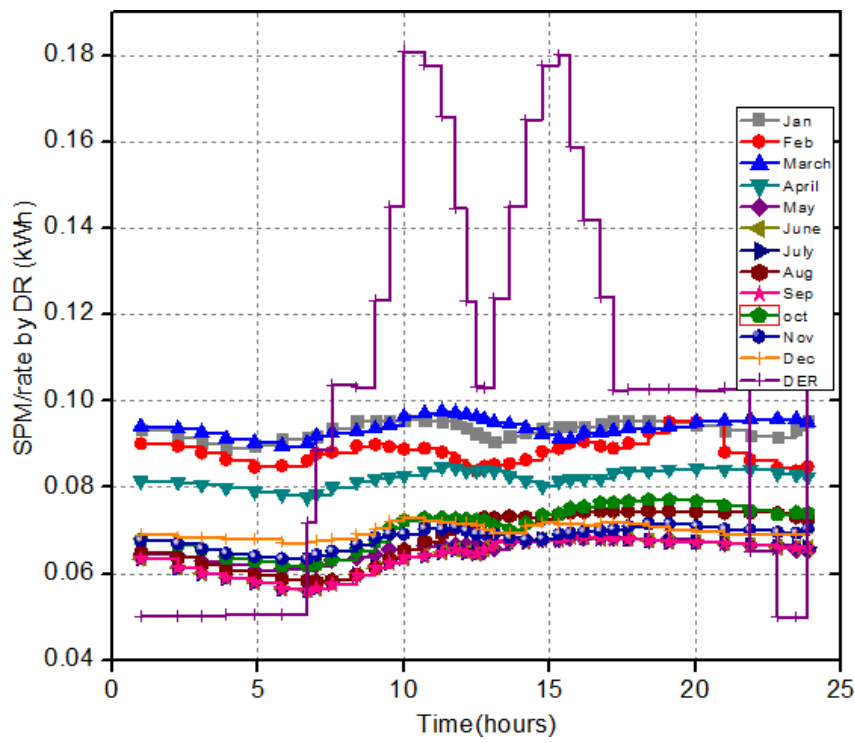

FIGURE 6. Electricity Rate Computed by the DR Program and Average SMP on Monthly Basis

\section{B. PREDICTIVE ANALYSIS}

Prediction models play a consequential role in revealing implicit knowledge or hidden pattern of the data and exploit that knowledge to devise effective policies [44]-[48]. For training, BD-LSTM uses a 10-fold cross-validation technique to predict energy load, energy consumption, PV generation, and energy cost, as shown in Figures (7-10), respectively. The figures shows the actual and predicted values for the said four predictive analyses. The prediction outcomes attained using RMSE (see equation 8). We have observed the individual and predicted results for all the predictions, as shown in Table 3. The figures exhibit a difference between actual and predicted outputs. The best value of RMSE is reported for PV generation prediction (1.26), followed by energy load (1.45) and energy consumption (1.98). Overall, the value of RMSE signifies good prediction behavior that can positively impact the energy-oriented prediction models and energy provider entities to form effective decision-making. The accurate estimation of energy load, energy consumption, and PV generation can help in the future for resource and load optimization as per a certain time.

\section{ENERGY COST OPTIMIZATION}

This section encompasses the outcomes attained by implementing the PSO-enabled energy cost objective function

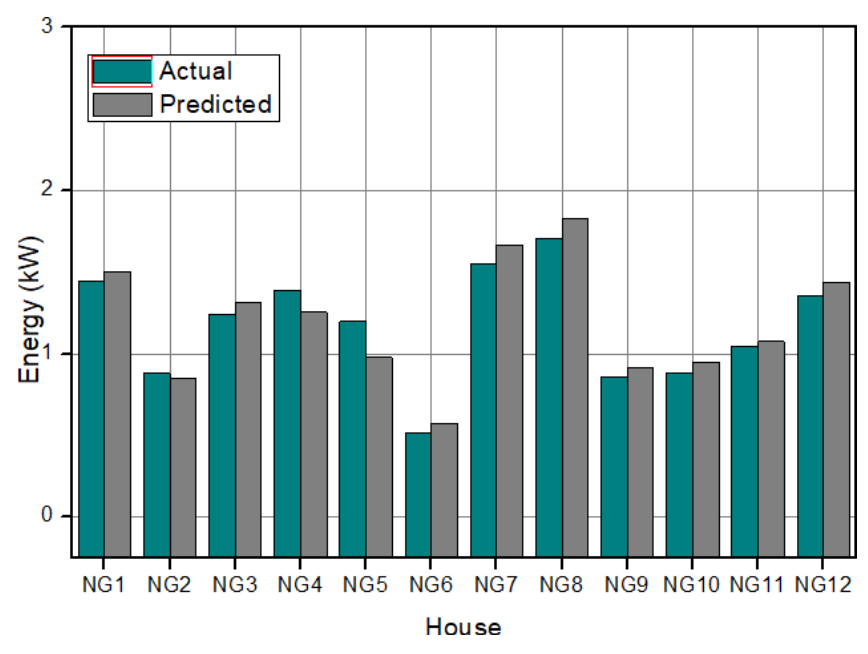

FIGURE 7. Actual and Predicted Energy Load Values for Nanogrid Houses

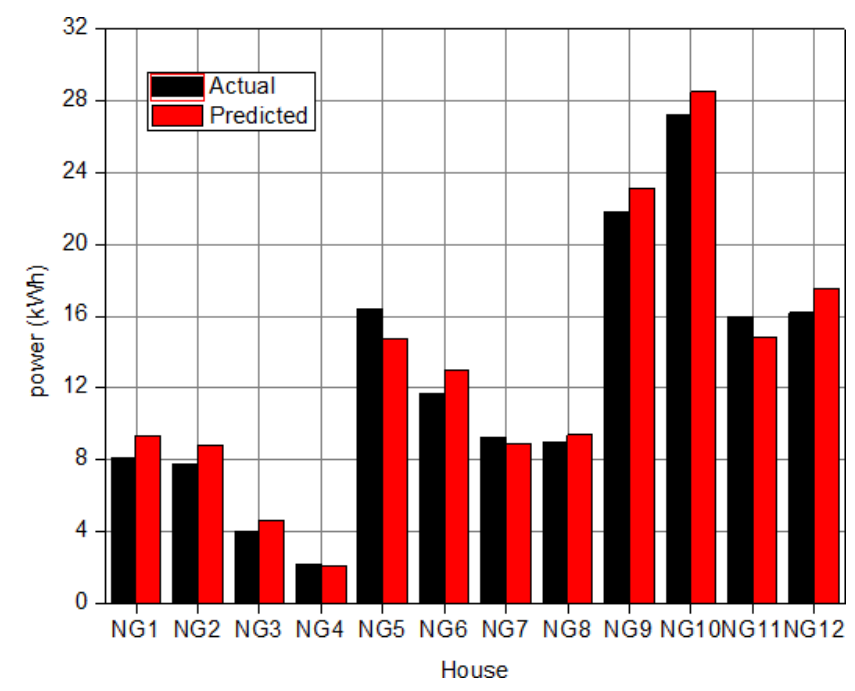

FIGURE 8. Actual and Predicted Energy Consumption Values for Nanogrid Houses

(explained in section 3). Figure 10 shows the energy cost results in three aspects: (1) actual energy cost, predicted energy cost, and optimized energy cost. The $\mathrm{X}$-axis shows the timestamp information, i.e., days of the week, and the $y$-axis shows energy price in the dollar (\$). The actual energy cost data is obtained from the SMP/DER, as explained in [44]. The graph exhibits average values computed for all the 12 nanogrid houses in the proposed energy trading framework. Predicted energy price may help to take on-time decisions related to energy cost before trading. Predicting energy price is helpful for individual prosumers and consumers to predict future market trends. Likewise, the optimal energy price is computed based on the objective function to find the optimal energy price. It is estimated from the graph that the PSO-based optimization function finds the optimal real-time energy price in between the original and predicted energy 


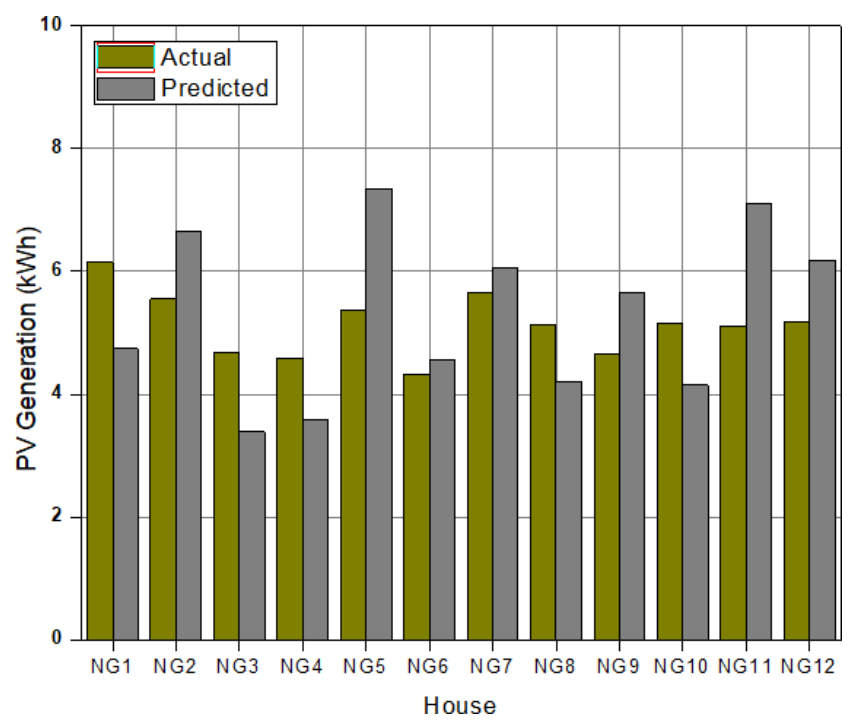

FIGURE 9. Actual and Predicted PV Generation Values for Nanogrid Houses

price. It an be inferred that optimal energy price can help in achieving the optimized real-time energy cost used in energy trading system.

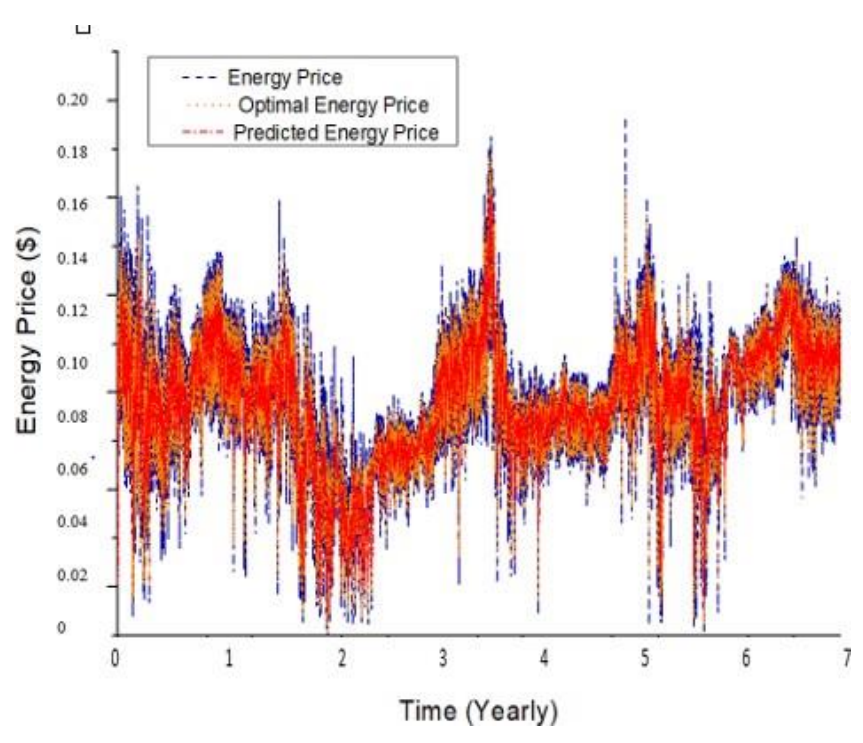

FIGURE 10. Actual, Predicted and Optimal Energy Cost for Nanogrid

\section{PERFORMANCE ANALYSIS OF ENERGY EXCHANGING MECHANISM}

This section encompasses the results attained by simulations considered for 12 nanogrids, as shown in Figure 11, 12 and 13 (the simulation results of 12 NGs is shown in three parts). The X-axis of the figures $(11,12,13)$ shows "Days" of Week and $\mathrm{Y}$-axis shows "Power(kW)".

The positive values exhibit that a nanogrid has acted as a prosumer and traded its surplus energy to other connected nanogrids in the network. In contrast, the negative values indicate that nanogrid has acted as a consumer and bought energy from other NG. It is evident that each nanogrid assumes a varying role amids the simulation. For instance, NG-10 assumed the consumer role as its produced PV energy is not self-sufficient to fulfill its energy requirements. On the other hand, the nanogrids 1,2 , and 4 behaved as a prosumer because load demands of these NGs are less than the respective PV energy; thus the surplus energy is employed for selling to the consumer NGs in need. In addition, the rest of the NGs have assumed alternate roles in the energy sharing process. The roles of NGs entirely depend on the amount of their respective produced energy. For instance, if a nanogrid has surplus PV energy, it can act as a prosumer; otherwise, it acts as a consumer NG.

Overall, the outcomes signify that the proposed model can successfully be implemented for small-scale nanogrids, connected in the form of a cluster/network.
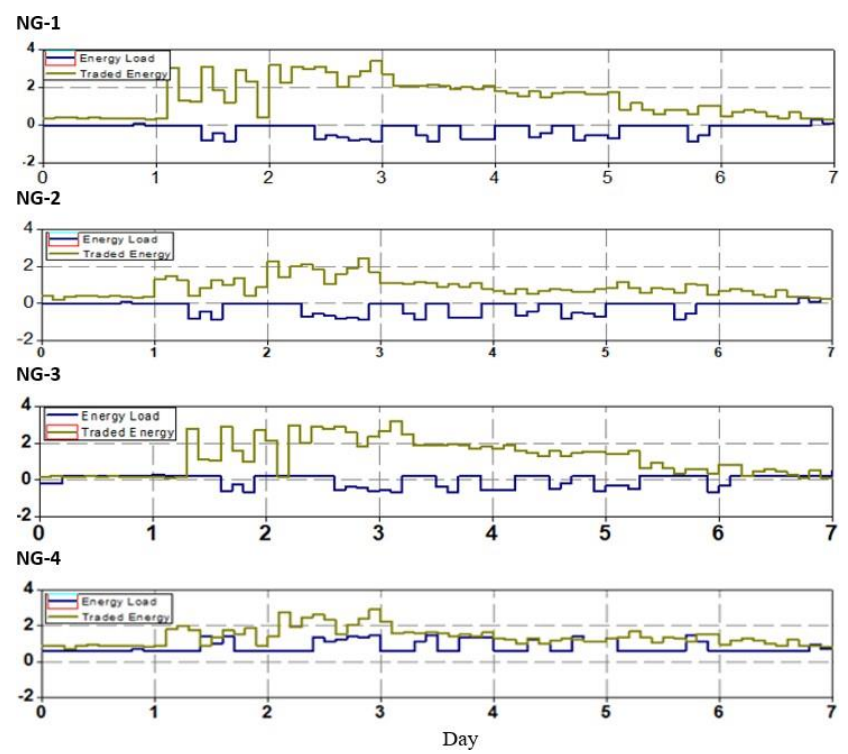

FIGURE 11. Energy Load and Traded Energy of NG1, NG2, NG3, and NG4.

\section{CONCLUSION}

Excess utilization of fossil-based energy resources is the leading cause of polluting the environment. This problem has made it a primary concern for householders to install renewable energy-based distributed energy resources (DERs) and energy storage systems. This article presented an intelligent energy trading model that contemplates important aspects overlooked by contemporary state-of-the-art in energy trading. We present a predictive optimal energy trading plan that focuses on two main factors: an intelligent timeaware energy sharing plan is formed among nanogrid clusters to decide the role of peers as prosumers and fosters the harnessing of PV generated energy for energy trading within a nanogrid cluster, and an objective function is designed to minimize nanogrid energy trading cost which takes predictive parameters as input and implements objective function using PSO algorithm. The study's outcomes are evaluated using 


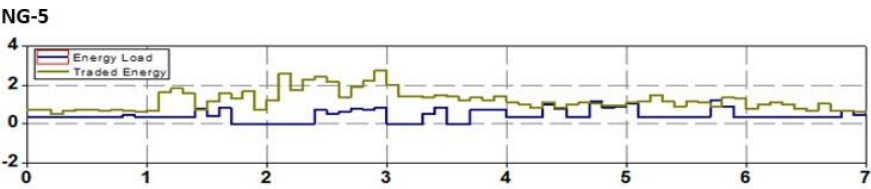

NG-6

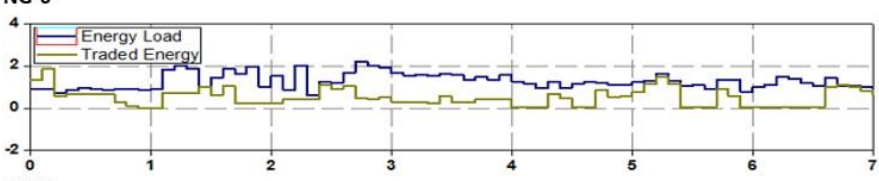

NG-7

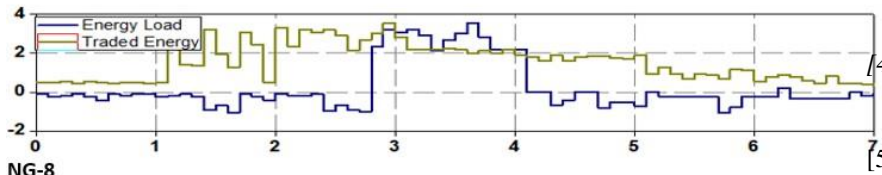

NG-8

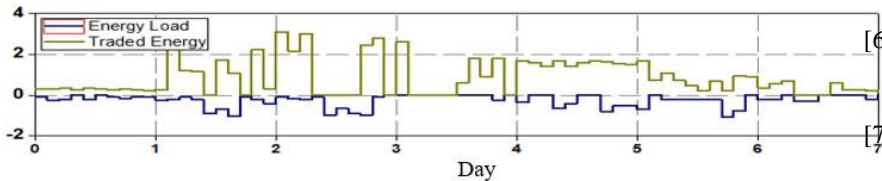

FIGURE 12. Energy Load and Traded Energy of NG5, NG6, NG7, and NG8.

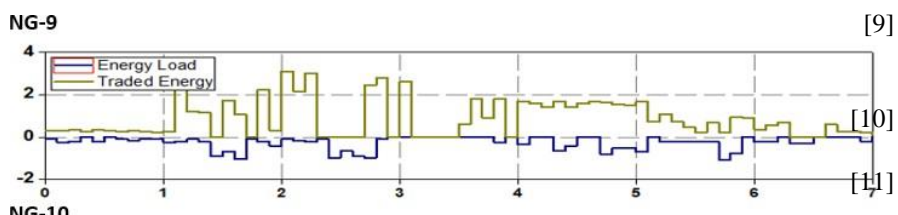

NG-10

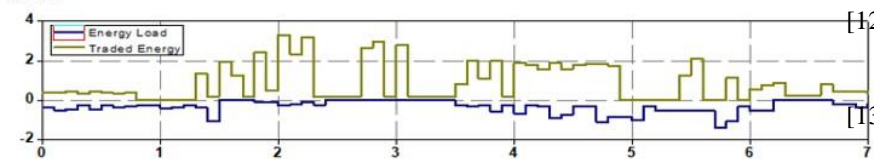

NG-11

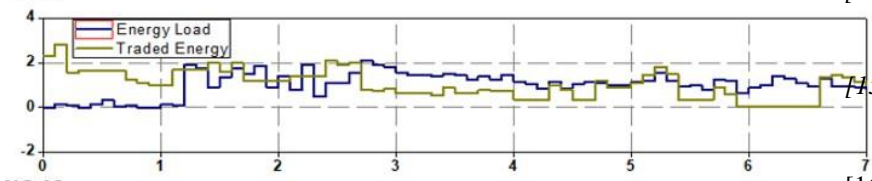

NG-12

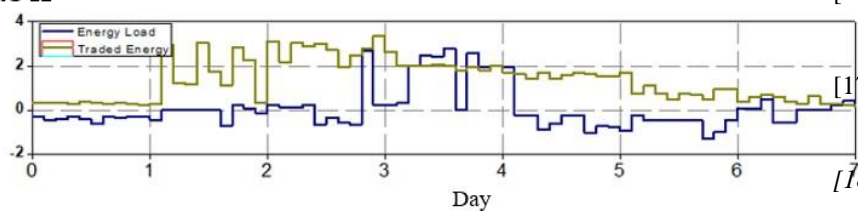

Day

FIGURE 13. Energy Load and Traded Energy of NG9, NG10, NG11, and NG12.

energy parameters of 12 nanogrid houses by conducting simulation. In addition, detailed analysis and prediction of important energy parameters, including energy load, energy consumption, and PV generation, is also performed using the BD-LSTM algorithm, validated using standard evaluation measure RMSE. The prediction outcomes can positively contribute to efficint decision making for smart grid-based systems. The detailed experiments via simulation revealed that the energy sharing plan has a tendency to meet the energy requirements of nanogrid house in the P2P cluster, and energy cost is reduced significantly

\section{REFERENCES}

[1] Bayram, I. S., Shakir, M. Z., Abdallah, M., Qaraqe, K. (2014, December). A survey on energy trading in smart grid. In 2014 IEEE Global Conference on Signal and Information Processing (GlobalSIP) (pp. 258-262). IEEE.

[2] Mengelkamp, E., Gärttner, J., Rock, K., Kessler, S., Orsini, L., Weinhardt, C. (2018). Designing microgrid energy markets: A case study: The Brooklyn Microgrid. Applied Energy, 210, 870-880.

[3] M. T. I. Khan, M. R. Yaseen, and Q. Ali, "Nexus between financial development, tourism, renewable energy, and greenhouse gas emission in high-income countries: A continent-wise analysis," Energy Econ., vol. 83, pp. $293_{3} 10$, Sep. 2019.

] M.-H. Kim, D. Kim, J. Heo, and D.-W. Lee, "Energy performance investigation of net plus energy town: Energy balance of the Jincheon eco-friendly energy town," Renew. Energy, vol. 147, pp. 1784,800, Mar. 2020.

5] J. Li, X. Zhang, S. Ali, and Z. Khan, "Eco-innovation and energy productivity: New determinants of renewable energy consumption," J. Environ. Manage., vol. 271, Oct. 2020, Art. no. 111028.

6] Z. Sen, Solar Energy Fundamentals and Modeling Techniques: Atmo- sphere, Environment, Climate Change and Renewable Energy. London, U.K.: SpringerVerlag, 2008.

7 ] G. C. van Kooten, "Economic analysis of feed-in tariffs for generating electricity from renewable energy sources," in Handbook Energy Climate Change. Victoria, BC, Canada: Univ. Victoria, Resource Economics and Policy, 2013.

[8] M. V. Kirthiga, S. A. Daniel, and S. Gurunathan, "A methodology for transforming an existing distribution network into a sustainable autonomous micro-grid," IEEE Trans. Sustain. Energy, vol. 4, no. 1, pp. 31-41, Jan. 2013.

[9] A. Werth, N. Kitamura, and K. Tanaka, "Conceptual study for open energy systems: Distributed energy network using interconnected DC nanogrids," IEEE Trans. Smart Grid, vol. 6, no. 4, pp. 1621-1630, Jul. 2015.

0] B. Nordman, "Nanogrids: Evolving our electricity systems from the bottom up," in Proc. Darnell Green Power Forum, Anaheim, CA, USA, 2009, pp. 1-6.

1] A. S. Tanenbaum and M. Van Steen, Distributed Systems. Upper Saddle River, NJ, USA: Prentice-Hall, 2007.

12] Liu, N., Yu, X., Fan, W., Hu, C., Rui, T., Chen, Q., Zhang, J. (2017). Online energy sharing for nanogrid clusters: A Lyapunov optimization approach. IEEE Transactions on Smart Grid, 9(5), 4624-4636.

Zhang, C., Wu, J., Zhou, Y., Cheng, M., Long, C. (2018). Peer-to-Peer energy trading in a Microgrid. Applied Energy, 220, 1-12.

[14] Z. Li, S. Bahramirad, A. Paaso, M. Yan, and M. Shahidehpour, "Blockchain for decentralized transactive energy management system in networked microgrids," Electr. J., vol. 32, no. 4, pp. 5872, May2019.

45] F. S. Ali, M. Aloqaily, O. Alfandi, and O. Ozkasap, "Cyberphysical blockchainenabled Peer-to Peer energy trading," Computer, vol. 53, no. 9, pp. 5665, Sep. 2020.

[16] K. K. Küster, A. R. Aoki, and G. Lambert-Torres, "Transaction-based operation of electric distribution systems: A review,” Int. Trans. Electr. Energy Syst., 2019, doi: 10.1002/2050-7038.12194

[17] C. Pop, T. Cioara, M. Antal, I. Anghel, I. Salomie, and M. Bertoncini, "Blockchain based decentralized management of demand response programs in smart energy grids," Sensors, vol. 18, no. 2, p. 162, Jan. 2018.

[18] J. J. Sikorski, J. Haughton, and M. Kraft, "Blockchain technology in the chemical industry: Machine-to-machine electricity market," Appl. Energy, vol. 195 , pp. $234_{2} 46$, Jun. 2017.

[19] S. Ahmad, Imran, F. Jamil, N. Iqbal, and D. Kim, "Optimal route recommendation for waste carrier vehicles for efficient waste collection: A step forward towards sustainable cities," IEEE Access, vol. 8, pp. 7787577887, 2020.

[20] F.Wahid, M. Fayaz, A. Aljarbouh, M. Mir, M. Aamir, and Imran, "Energy Consumption Optimization and User Comfort Maximization in Smart Buildings Using a Hybrid of the Firefly and Genetic Algorithms", Energies, vol. 13, no. 17, p. 4363, Aug. 2020.

[21] S. Ahmad, Imran, N. Iqbal, F. Jamil, and D. Kim, "Optimal policy-making for municipalwaste management based on predictive model optimization," IEEE Access, vol. 8, pp. 218458, 18469, 2020.

[22] S. Ahmad and D. Kim, "Design and implementation of thermal comfort system based on tasks allocation mechanism in smart homes," Sustainabil- ity, vol. 11, no. 20, p. $5849,2019$.

23] J. Matamoros, D. Gregoratti, and M. Dohler, "Microgrids energy trading in islanding mode," in Proc. IEEE 3rd Int. Conf. Smart Grid Commun. (SmartGridComm), Nov. 2012, pp. $49_{5} 4$. 
[24] Moradzadeh, B., Tomsovic, K., 2013. Two-stage residential energy management considering network operational constraints. IEEE Trans. Smart Grid 4 (4), 2339-2346. http://dx.doi.org/10.1109/TSG.2013.2265313.

[25] Lauinger, D., Caliandro, P., Kuhn, D., et al., 2016. A linear programming approach to the optimization of residential energy systems. J. Energy Storage 7, 24-37.

[26] H. Wang, J. X. Zhang, and F. Li, "Incentive mechanisms to enable fair renewable energy trade in smart grids," in Proc. 6th Int. Green Sustain. Comput. Conf. (IGSC), Dec. 2015, pp. $1_{6}$.

[27] W. Lee, L. Xiang, R. Schober, and V. W. S. Wong, "Direct electricity trading in smart grid: A coalitional game analysis," IEEE J. Sel. Areas Commun., vol. 32, no. 7, pp. $1398_{1} 411$, Jul.2014.

[28] Y. Wu, X. Sun, X. Tan, L. Meng, L. Yu, W.-Z. Song, and D. H.-K. Tsang, "Cooperative distributed energy generation and energy trading for future smart grid," in Proc. 33rd Chin. Control Conf., Jul. 2014, pp. 81508157.

[29] Vahedipour-Dahraie, M., Rashidizadeh-Kermani, H., Shafie-Khah, M., Siano, P., 2020. Peer-to-peer energy trading between wind power producer and demand response aggregators for scheduling joint energy and reserve. IEEE Syst. J. 15 (1), 705-714.

[30] Umer, K., Huang, Q., Khorasany, M., Afzal, M., Amin, W., 2021. A novel communication efficient peer-to-peer energy trading scheme for enhanced privacy in microgrids. Appl. Energy 296, 117075.

[31] Paudel, A., Sampath, L., Yang, J., Gooi, H.B., 2020. Peer-to-peer energy trading in smart grid considering power losses and network fees. IEEE Trans. Smart Grid 11 (6), 4727-4737.

[32] Esmat, A., de Vos, M., Ghiassi-Farrokhfal, Y., Palensky, P., Epema, D., 2021 A novel decentralized platform for peer-to-peer energy trading market with blockchain technology. Appl. Energy 282, 116123.

[33] N. Iqbal, F. Jamil, S. Ahmad, and D. Kim, "Toward effective planning and management using predictive analytics based on rental book data of academic libraries", IEEE Access, vol. 8, pp. 81978 $1996,2020$.

[34] N. Iqbal, F. Jamil, S. Ahmad, and D. Kim, "A novel blockchainbased integrity and reliable veterinary clinic information management system using predictive analytics for provisioning of quality health services," IEEE Access, vol. 9, pp. $8069_{8} 098,2021$

[35] Kanakadhurga, D., Prabaharan, N. (2021). Demand response-based peer-to-peer energy trading among the prosumers and consumers. Energy Reports.

[36] M. A. Karim, J. Currie, and T.-T. Lie, "Amachine learning based optimized energy dispatching scheme for restoring a hybrid microgrid," Electr. Power Syst. Res., vol. 155, pp. 2062 15, Feb. 2018.

[37] A. Chaouachi, R. M. Kamel, R. Andoulsi, and K. Nagasaka, "Multiobjective intelligent energy management for a microgrid," IEEE Trans. Ind. Electron., vol. 60, no. 4, pp. 1688 699, Apr. 2013.

[38] Ma, K., Yao, T., Yang, J., Guan, X., 2016. Residential power scheduling for demand response in smart grid. Int. J. Electr. Power Energy Syst. 78, 320-325.

[39] Zhang, Z., Li, R., Li, F., 2019. A novel peer-to-peer local electricity market for joint trading of energy and uncertainty. IEEE Trans. Smart Grid 11 (2), 1205-1215.

[40] Anoh, K., Maharjan, S., Ikpehai, A., Zhang, Y., Adebisi, B., 2019. Energy peertopeer trading in virtual microgrids in smart grids: A game-theoretic approach. IEEE Trans. Smart Grid 11 (2), 1264-1275.

[41] Alam, M.R., St-Hilaire, M., Kunz, T., 2019. Peer-to-peer energy trading among smart homes. Appl. Energy 238, 1434-1443.

[42] Paudel, A., Chaudhari, K., Long, C., Gooi, H.B., 2018. Peer-to-peer energy trading in a prosumer-based community microgrid: A game-theoretic model. IEEE Trans. Ind. Electron. 66 (8), 6087-6097.

[43] Tushar, W., Saha, T.K., Yuen, C., Azim, M.I., Morstyn, T., Poor, H.V., Niyato, D., Bean, R., 2020. A coalition formation game framework for peer-to-peer energy trading. Appl. Energy 261, 114436.

[44] Lee, H.G., et al.: Design algorithm for optimum capacity of ESS connected with PVs under the RPS program. IEEE Access 6, 45899-45906 (2018)

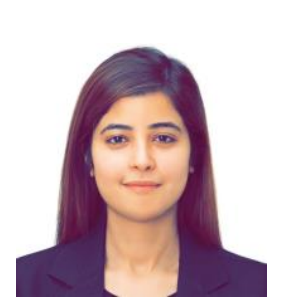

FAIZA QAYYUM is pursuing Ph.D. in Computer Engineering from Jeju National University (JNU), South Korea. She received her MS degree in Computer Science from Capital University of Science and Technology (CUST), Islamabad, Pakistan in 2017. Her research areas include machine learning, data mining, smart grid optimization, web mining, information retrieval etc. She has been associated with academia since last four years where and projects at national and international level. she has been involved in preparing RD proposals

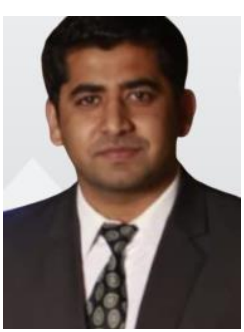

HARUN JAMIL received the B.S.c degree in electronic engineering from the Capital University of Science and the M.S.EE degree in electrical engineering from the Air University, Islamabad, Pakistan, in 2019. He is currently pursuing the Ph.D. degree with the Department of Electronic Engineering, Jeju National University, South Korea. His research work mainly focused on the indoor localization, data fusion techniques, nanogrid, energy optimization and prediction.

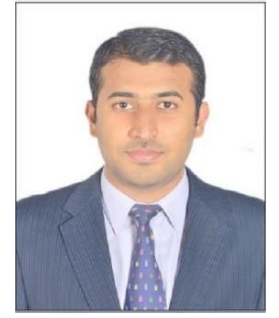

mobile computing.
FAISAL JAMIL is currently pursuing Ph.D. in the Department of Computer Engineering at Jeju National University, the Republic of Korea. He received his MS in Computer Science from University of Engineering and Technology, Taxila Pakistan in 2018. He did his BS in Computer Science from the Capital University of Science. His research work mainly focused on Internet of Things application, Blockchain application, energy optimization and prediction intelligent service, and

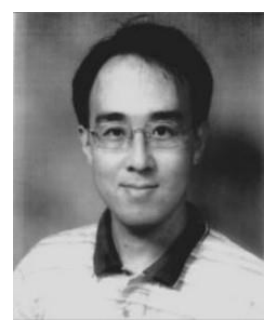

DOHYEUN KIM received the B.S. degree in electronics engineering from Kyungpook National University, South Korea, in 1988, and the M.S.and Ph.D. degrees in information telecommunication from Kyungpook National University, South Korea, in 1990 and 2000, respectively. He was with the Agency of Defense Development (ADD),from 1990 to 1995. Since 2004, he has been with Jeju National University, South Korea, where he is currently a Professor with the Department of Computer Engineering. From 2008 to 2009, he was a Visiting Researcher with the Queensland University of Technology, Australia. His research interests include sensor networks, M2M/IOT, energy optimization and prediction, intelligent service, and mobile computing. 